Fetal Diagnosis and Therapy

\title{
Congenital Idiopathic Dilatation of the Right Atrium: Antenatal Appearance, Postnatal Management, Long-Term Follow-Up and Possible Pathomechanism
}

\author{
Sigrun R. Hofmann ${ }^{\mathrm{a}}$ Antje Heilmann ${ }^{\mathrm{a}}$ Hans J. Häusler ${ }^{\mathrm{a}}$ Ingo Dähnert ${ }^{\mathrm{c}}$ \\ Gabriele Kamin $^{\text {b }}$ Robert Lachmann ${ }^{\text {b }}$ \\ Departments of a Pediatrics and ${ }^{\mathrm{b}}$ Gynecology and Obstetrics, University Hospital Carl Gustav Carus, \\ Technical University of Dresden, Dresden, and ${ }^{\mathrm{C}}$ Heart Center, University of Leipzig, Leipzig, Germany
}

\section{Key Words}

Aneurysm • Dilatation $\cdot$ Congenital $\cdot$ Right atrium $\cdot$

Echocardiography

\begin{abstract}
Introduction: Idiopathic dilatation of the right atrium (IDRA) is a rare abnormality usually detected by chance at any time between antenatal and adult life. It is defined as isolated enlargement of the right atrium in the absence of other cardiac lesions causing right atrial dilatation. IDRA can be associated with atrial arrhythmia and systemic embolism. The clinical presentation shows high variability ranging from the lack of any symptoms up to cardiac failure. Methods/Results: We describe 2 children with antenatally diagnosed IDRA, the intrauterine course in 1 case, the postnatal management and its long-term follow-up. There has been no need for surgical intervention so far because of the lack of arrhythmias and no further progression of right atrial diameters. Thrombus formation in the right atrium, which is a potential risk for pulmonary embolism, led us to initiate anticoagulation in our cases to prevent such complications. Furthermore, we suggest one possible pathomechanism of congenital right atrial dilatation. Conclusion: Optimal management of severe IDRA
\end{abstract}

\section{KARGER}

Fax +4161306 1234

E-Mail karger@karger.ch

www.karger.com
C) 2012 S. Karger AG, Basel

$1015-3837 / 12 / 0324-0256 \$ 38.00 / 0$

Accessible online at:

www.karger.com/fdt depends on the individual case. Long-term follow-up of these patients is necessary to monitor a possible further progression of right atrial size and occurrence of arrhythmias. As a possible pathomechanism, a functional partial anomalous pulmonary venous insertion may imitate a structural abnormal pulmonary vein connection in some idiopathic cases of congenital right atrial dilatation.

Copyright $\odot 2012$ S. Karger AG, Basel

\section{Introduction}

So far, idiopathic dilatation of the right atrium (IDRA) is a congenital anomaly with unknown pathogenesis. It is defined as isolated enlargement of the right atrium (RA) in the absence of other cardiac lesions known to cause right atrial dilatation $[1,2]$. There is no consensus on whether it is congenital or acquired [3]. Some prefer to call it idiopathic dilatation of the RA [1], while others label it as congenital enlargement of the RA [4] or congenital right atrial diverticulum [5]. There are clear characteristics distinguishing an aneurysm, 'as a dilatation of the atrium involving all layers of the atrial wall, from a diverticulum, an entry of fibromuscular strands across 
the atrial wall' [6]. However, in the literature this clear distinction is not made continuously, as one can see in the definition by Chockalingam et al. [7]: 'an atrial aneurysm, or diverticulum, is an aneurysmal outpouching from an otherwise normal atrium'. Therefore, because of inconsistent terminology, the first description of IDRA was cited differently by Borrichin in 1676 [8], Semans and Taussig in 1938 (cited by Imren et al., 2006 [4]) and Morrow and Behrendt [9] in 1968. Bailey (cited by Forbes et al., 2007 [1]) was the first to excise a diverticulum of the RA.

The clinical spectrum ranges from the incidental finding of cardiomegaly on chest radiography to antenatal diagnosis because of significant atrial tachyarrhythmias. Most of the IDRA patients are asymptomatic. However, some patients develop arrhythmias or symptoms of congestive heart failure. Since there have been reports of significant symptoms and even sudden death [10], information about the management of this rare disease is essential to correct diagnosis, appropriate patient survey as well as treatment. We describe 2 children with antenatally diagnosed IDRA, providing long-term follow-up on our cases and suggesting a possible pathomechanism for this rare condition.

\section{Methods}

Two children with antenatally diagnosed IDRA, the intrauterine course in 1 case, the postnatal management and its long-term follow-up are described. Because of the lack of arrhythmias and no further progression of right atrial diameters so far, there has been no need for surgical intervention. Thrombus formation in the RA with the potential risk for pulmonary embolism has been described by others [9], leading us to initiate anticoagulation in our cases. Guided by an interesting intrauterine finding in case 1, we suggest a possible pathomechanism of congenital right atrial dilatation.

\section{Case 1}

A 21-year-old gravida 1 para 0 was referred to our outpatient clinic for second-trimester screening at $20+5$ weeks of gestation. Her medical and obstetrical history was uneventful. Family history did not show any cardiac diseases or chromosomal abnormalities. There have been no extracardiac malformations. Intrauterine fetal growth and well-being parameters appeared normal. Echocardiography of the fetus showed an abnormal 4-chamber view (4CV; fig. 1a) with an increased cardiothoracic circumference ratio of 0.571 and an especially enlarged RA. During the intrauterine course the known RA dilatation persisted (fig. 1a). In addition, we were able to demonstrate an abnormal left-to-right (L-R) shunt across the foramen ovale demonstrated in figure $1 \mathrm{~b}$. A female infant was delivered at term (gestational age $39+0$ weeks) via spontaneous vaginal delivery with a birth weight of 3,020 g (Apgar 8/9/9). Postnatal two-dimensional transthoracic
Table 1. Parameters measured during cardiac catheterization in case 1 at the age of 10 months

\begin{tabular}{|c|c|c|c|c|}
\hline & \multicolumn{3}{|c|}{ Pressure, $\mathrm{mm} \mathrm{Hg}$} & \multirow{2}{*}{$\begin{array}{l}\mathrm{SaO}_{2} \\
\%\end{array}$} \\
\hline & middle & $\begin{array}{l}\text { systolic/diastolic } \\
\text {-end-diastolic }\end{array}$ & $\begin{array}{l}\text { systolic/diastolic } \\
\text {-middle }\end{array}$ & \\
\hline RA & 2 & & & \\
\hline RV & & $20 / 0-2$ & & \\
\hline LA & 4 & & & \\
\hline LV & & $85 / 0-7$ & & \\
\hline PA & & & $15 / 5-9$ & \\
\hline SVC & & & & 70.5 \\
\hline IVC & & & & 81.4 \\
\hline \multicolumn{5}{|c|}{$\mathrm{Q}_{\mathrm{p}}: \mathrm{Q}_{\mathrm{s}}=1.0$} \\
\hline \multicolumn{5}{|c|}{$\begin{array}{l}\mathrm{RA}=\text { Right atrium; } \mathrm{RV}=\text { right ventricle; } \mathrm{LA}=\text { left atrium; } \\
\mathrm{LV}=\text { left ventricle; } \mathrm{PA}=\text { pulmonary artery; } \mathrm{SVC}=\text { superior vena } \\
\text { cava; } \mathrm{IVC}=\text { inferior vena cava; } \mathrm{Q}_{\mathrm{p}}: \mathrm{Q}_{\mathrm{s}}=\text { ratio of pulmonic blood } \\
\text { flow }\left(\mathrm{Q}_{\mathrm{p}}\right) \text { to systemic blood flow }(\mathrm{Qs}) \text {. }\end{array}$} \\
\hline
\end{tabular}

echocardiography demonstrated that the RA was dilated massively with low blood flow velocity and spontaneous contrast within the cavity but without signs of intracardiac thrombus formation (fig. 1c). Thrombosis prophylaxis with salicylic acid was started. Alongside a patent foramen ovale with persistent L-R shunt, the remainder of the intracardiac anatomy, including the tricuspid valve, was normal. Particularly, there was no tricuspid regurgitation noted in ante- or postnatal echocardiograms.

At 4 weeks, the child remained well (body weight 3,970 g) and the echocardiogram was unchanged, showing the RA with an area of $10 \mathrm{~cm}^{2}$ (compared to left atrial area of $3.2 \mathrm{~cm}^{2}$ ) (fig. 1d). Chest radiography disclosed an enlarged cardiac silhouette due to an enlarged RA (not shown). At the age of 4 months the RA area was $18 \mathrm{~cm}^{2}$ (fig. 1d). The electrocardiogram (ECG) showed sinus rhythm. At 10 months the RA area increased to $24 \mathrm{~cm}^{2}$ and a cardiac catheterization (Heart Center, University of Leipzig, Germany) confirmed the diagnosis of isolated and IDRA, showing no further intracardiac abnormalities (fig. 1e), especially no anatomical partial anomalous pulmonary venous connection. The pulmonary artery pressure measured during cardiac catheterization was 15/5-9 $\mathrm{mm} \mathrm{Hg}$ (systolic/diastolic-middle). There was no measurable shunt through the small patent foramen ovale $\left(\mathrm{Q}_{\mathrm{p}}: \mathrm{Q}_{\mathrm{s}}=1.0\right)$ (table 1).

Between ages 2 and 4, the RA area stayed relatively stable in relation to normal body growth, totaling $34 \mathrm{~cm}^{2}$ now (fig. 1d). Subsequent Holter monitoring showed sinus rhythm and no atrial arrhythmia. The child's growth, development, and exercise tolerance have all remained normal. The child is now 4 years of age without any clinical symptoms.

Case 2

Diagnosis of RA dilatation was made during fetal life by echocardiography (in a different hospital). Postnatal two-dimensional echocardiogram at the age of 2 weeks confirmed the presence of 

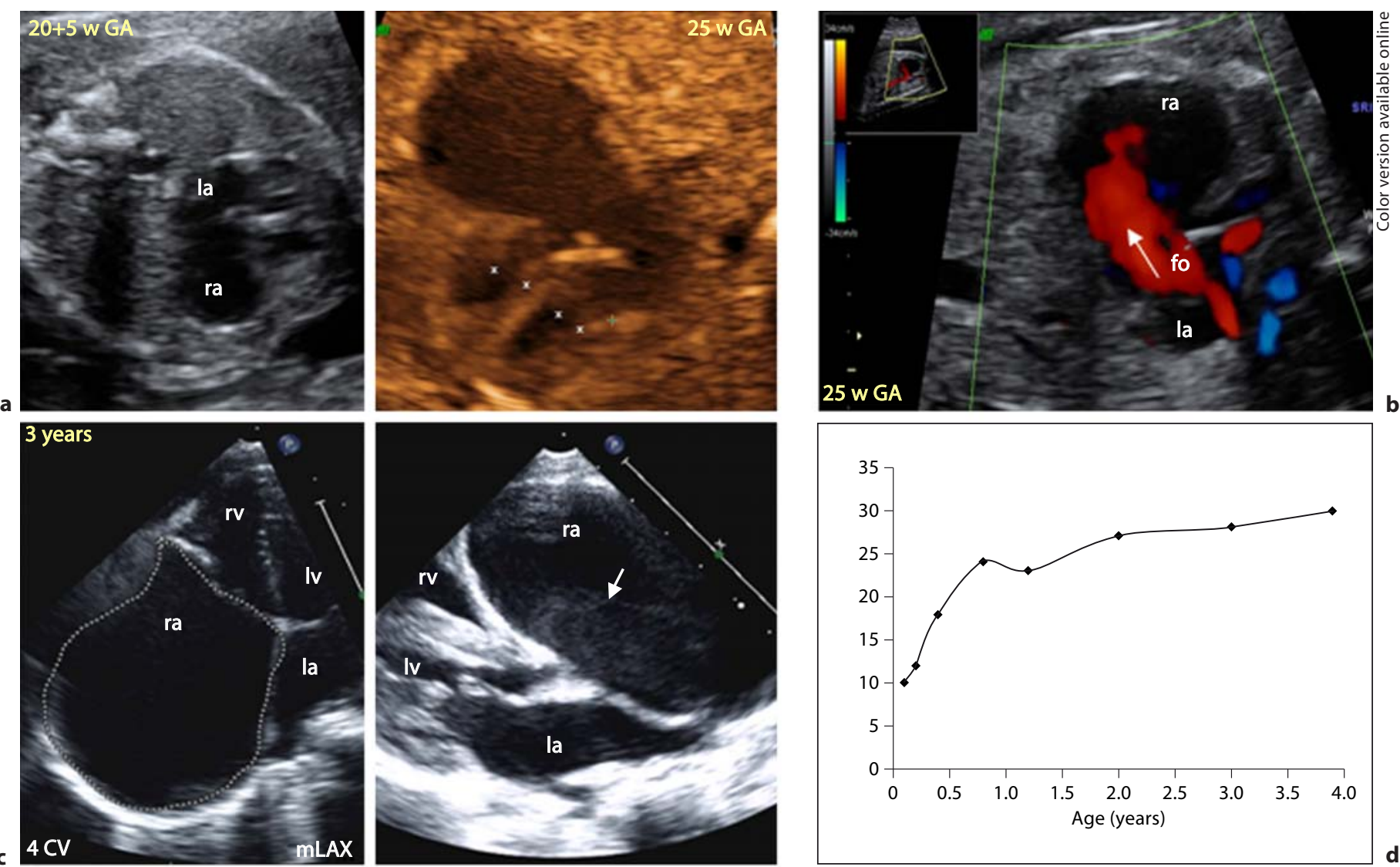

b
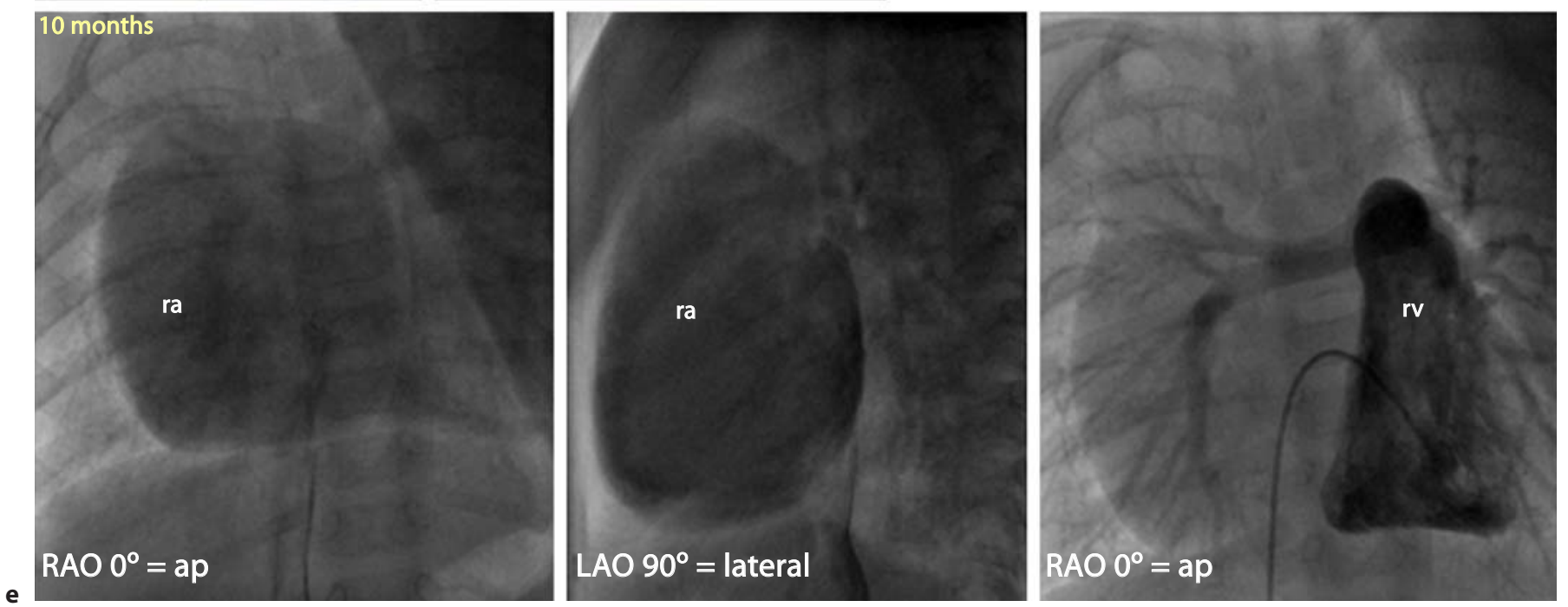

Fig. 1. Case 1. a Prenatal echocardiography at $20+5$ weeks of gestation (w GA) showing the abnormal $4 \mathrm{CV}$ with an increased cardiothoracic circumference ratio of 0.571 due to massive right atrial dilatation and intrauterine course. b Abnormal L-R shunt across the foramen ovale (white arrow) shown at 25 weeks of gestation. c Postnatal transthoracic echocardiography at the age of 3 years. $4 \mathrm{CV}$ and modified long axis (mLAX) of the heart demonstrating a very large RA, normal right ventricle and normal leftsided chambers. Spontaneous echo contrast (white arrow) was present within the dilated RA as a sign of low flow. d Diagram

showing the right atrial dimension $\left(\mathrm{cm}^{2}\right)$ over a 4-year period. There is no evidence of further progressive right atrial enlargement. The $y$-axis shows the right atrial dimension in $\mathrm{cm}^{2}$. e X-ray during cardiac catheterization at the age of 10 months excluding further intracardiac anomalies. Contrast image of the RA in anterior-posterior (ap) projection (left panel), lateral projection (middle panel), and contrast image of the right ventricle (rv) in ap projection on the right panel. $\mathrm{ra}=$ Right atrium (RA); rv = right ventricle; la = left atrium; lv = left ventricle; fo = foramen ovale. 

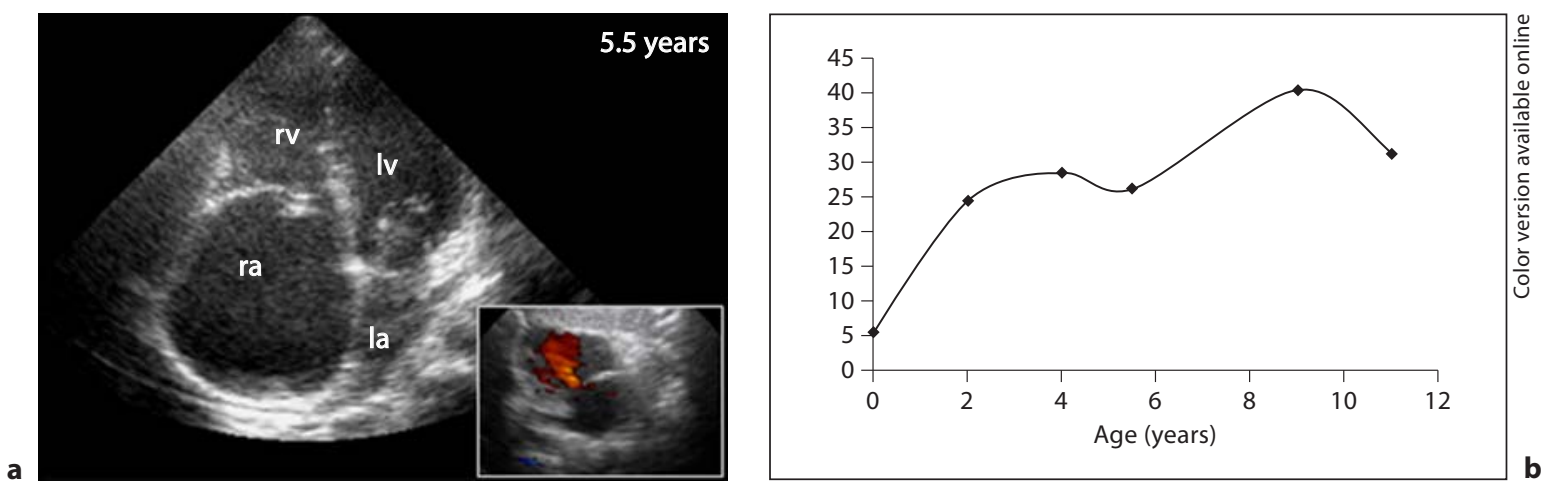

Fig. 2. Case 2. a Transthoracic echocardiography at the age of 5.5 years (4CV of the heart) showing cardiomegaly due to right atrial dilatation. b Diagram showing the right atrial dimension $\left(\mathrm{cm}^{2}\right)$ over a 7-year period. The size has been measured two-dimensionally in the apical 4CV and by planimetry. The y-axis shows the planimetered right atrial dimension in $\mathrm{cm}^{2} . \mathrm{ra}=$ Right atrium $(\mathrm{RA}) ; \mathrm{rv}=$ right ventricle; la = left atrium; lv = left ventricle.

Table 2. Measurements of right atrial size including major-axis and minor-axis lengths and planimetered areas in $4 \mathrm{CV}$ (at end-systole) for both patients

\begin{tabular}{|c|c|c|c|c|c|c|c|}
\hline & \multirow{2}{*}{$\begin{array}{l}\text { Age } \\
\text { years }\end{array}$} & \multicolumn{3}{|c|}{ Right atrial dimension } & \multirow{2}{*}{$\begin{array}{l}\text { BW } \\
\mathrm{kg}\end{array}$} & \multirow{2}{*}{$\begin{array}{l}\mathrm{BL} \\
\mathrm{cm}\end{array}$} & \multirow{2}{*}{$\begin{array}{l}\text { BSA } \\
\mathrm{m}^{2} \text { (Haycock) }\end{array}$} \\
\hline & & $\begin{array}{l}\text { major-axis } \\
\mathrm{cm}\end{array}$ & $\begin{array}{l}\text { minor-axis } \\
\mathrm{cm}\end{array}$ & $\begin{array}{l}\text { planimetered } \\
\text { area }(4 \mathrm{CV}), \mathrm{cm}^{2}\end{array}$ & & & \\
\hline \multirow[t]{9}{*}{ Patient 1} & 0.1 & 3.5 & 2.85 & 10 & 3.97 & 50 & 0.24 \\
\hline & 0.2 & 3.8 & 3.7 & 12 & 5.4 & 56 & 0.3 \\
\hline & 0.4 & 4.5 & 3.8 & 18 & 7.5 & 66 & 0.38 \\
\hline & 0.8 & 5.8 & 4.2 & 24 & 9.49 & 72.8 & 0.45 \\
\hline & 1.20 & 5.7 & 4.1 & 23 & 10.10 & 77.5 & 0.47 \\
\hline & 2 & 5.8 & 4.6 & 27 & 12 & 86 & 0.54 \\
\hline & 3 & 5.9 & 4.85 & 28 & 14.5 & 97 & 0.63 \\
\hline & 3.5 & 6.2 & 5.4 & 34 & 15.2 & 100 & 0.65 \\
\hline & 4 & 6.2 & 5.4 & 34 & 17.4 & 104 & 0.71 \\
\hline \multirow[t]{6}{*}{ Patient 2} & 0 & 2.6 & 2.2 & 5.72 & 3.8 & 52 & 0.24 \\
\hline & 2 & 5.3 & 4.6 & 24.38 & 15 & 97.5 & 0.64 \\
\hline & 4 & 5.5 & 5.2 & 28.6 & 18 & 107 & 0.73 \\
\hline & 5.50 & 5.7 & 4.6 & 26.22 & 21.6 & 117 & 0.84 \\
\hline & 9 & 6.6 & 6.1 & 40.26 & 34 & 139 & 1.14 \\
\hline & 11 & 5.8 & 5.4 & 31.32 & 42 & 152 & 1.33 \\
\hline
\end{tabular}

$4 \mathrm{CV}=$ Four-chamber view; BSA = body surface area; BW = body weight; $\mathrm{BL}=$ body length.

a large RA $(26 \times 22 \mathrm{~mm})$. The female child was referred to our hospital at the age of 4 . Transthoracic echocardiography at this age showed the known massively dilated RA measuring $55 \times 52$ $\mathrm{mm}$ in the anterior-posterior plane (fig. 2b; table 2). There was only mild regurgitation of a normal tricuspid valve. There was a small fenestrated atrial septal defect from the secundum type with small L-R shunt, which persisted over the years (fig. 2a). Ventricular size and function were normal, as was the remainder of the cardiac anatomy. At the age of 5.5 years the RA dimension was almost unchanged $(57 \times 46 \mathrm{~mm}$; fig. $2 \mathrm{a}$, b; table 2$)$. Holter monitoring showed normal ECG, and ergometry was normal. At the age of 9, the RA dimension was $66 \times 61 \mathrm{~mm}$ (left atrium $46 \times 27$ $\mathrm{mm}$; fig. $2 \mathrm{~b}$; table 2). Two years later, at the age of 11, the RA dimension showed slight regression $(54 \times 58 \mathrm{~mm})$ in the $4 \mathrm{CV}$ (fig. 2b; table 2). There was no sign of cardiac failure. The physical strain remained normal and subsequent ECGs did not show any abnormalities. 


\section{Discussion}

Congenital IDRA is a rare condition, reported in fetuses [11, 12], children [1, 13], infants [1] and in adults [14]. There are only 31 reports in the literature about IDRA or congenital RA aneurysm. Only 12 out of these 31 reports describe cases which have been detected antenatally, in newborns or at the stage of early infancy $[1,4,11,13,15-$ 24].

It is difficult to estimate the true incidence of the disease, since most children are asymptomatic [13] and diagnosis is often made incidentally due to cardiomegaly on a chest X-ray. When symptoms are present, they may include palpitations, arrhythmia, non-specific chest pain, dyspnea, fatigue, and syncope.

In some reports, IDRA is claimed to be a benign condition [13] without reduction of expectation of life, but others suggest inevitable progression to right heart failure. The resulting atrial arrhythmias evolve in a recurring way, increasing the potential risk of systemic or pulmonary embolism. Blondheim et al. [8] hypothesize 'that there may be two types of IDRA: one secondary to a degenerative process of unknown etiology affecting the atrial myocardium' (apoptotic process), the other 'a congenital absence of atrial myocardium and perhaps conduction tissue'. The first condition is claimed to have a more benign course, while the second may have associated conduction defects and poor long-term prognosis, including sudden death [25].

Interestingly, in our first described case we were able to show antenatally an abnormal L-R shunt over the foramen ovale (fig. 1b), guiding us to the working diagnosis 'functional' partial abnormal pulmonary venous connection. This means that the pulmonary veins are anatomically normally connected to the left atrium. However, there might be an uncommon angle of pulmonary vein insertion leading to a blood flow through the fossa ovalis. This concept of abnormal insertion angle of veins into the heart has already been proposed for fetuses with left-sided liver-up congenital diaphragmatic hernia [26]. Postnatally, there was also a L-R shunt through the foramen ovale, which is very often seen in completely normal newborns. However, in combination with the antenatal images, it might be a possible explanation of the right atrial dilatation. Postnatally, after the shunt through the interatrial septum got smaller, the RA size stayed stable in relation to body growth (fig. 1d). In the second case, similar findings are visible postnatally (fig. 2). However, assumptions are difficult to make due to the missing antenatal data.
Because of its rare occurrence, IDRA may easily be confused with other anomalies that lead to RA enlargement, such as Ebstein's anomaly [3, 27]. Transthoracic echocardiography yields a definite diagnosis in most cases, as it did in our cases. Nevertheless, transesophageal echocardiography, cardiac catheterization, computed tomography, and cardiac magnetic resonance imaging are other imaging modalities that might be helpful. Transesophageal echocardiography is particularly useful for detecting thrombus in the RA. However, there is a small risk of aneurysmal rupture using this invasive technique [4].

Surgical resection, anticoagulation, catheter-based ablation, and watchful waiting without medical intervention, are therapeutic options for RA enlargement and associated tachyarrhythmia. Patients with arrhythmias have been treated successfully with right reduction atrioplasty, but the arrhythmias may recur [3]. It still remains controversial whether to excise the aneurysm or not $[3$, 28]. Some patients manage quite well surgically and others non-surgically [3]. Thrombus formation in the RA, which is a potential risk for pulmonary embolism, has been reported [9]. Therefore, anticoagulant therapy should be considered upon diagnosis of IDRA in order to prevent such complications.

Only in case 1 was an additional cardiac catheterization performed to exclude any further cardiac anomalies, such as a partial abnormal pulmonary venous return to the right heart. Lacking arrhythmias and progression in RA diameters, there has been no need for surgical intervention. Nevertheless, long-term follow-up of these patients with repeated Holter ECG monitoring is necessary to monitor a possible further progressive RA dilatation and occurrence of arrhythmias.

\section{Conclusion}

In conclusion, IDRA is a rare congenital heart disease. The clinical presentation shows high variability, ranging from the lack of any symptoms to cardiac failure. Complications are edema, arrhythmia or congestive heart failure, as well as systemic embolism. We described 1 case which might explain the pathophysiology in some idiopathic cases of congenital RA dilatation. 'Functional' partial abnormal pulmonary venous connection, described as an uncommon angle of pulmonary vein insertion into the left atrium, may imitate an anatomically incorrect pulmonary venous connection into right heart structures. 


\section{References}

$>1$ Forbes K, Kantoch MJ, Divekar A, Ross D, Rebeyka IM: Management of infants with idiopathic dilatation of the right atrium and atrial tachycardia. Pediatr Cardiol 2007;28: 289-296.

-2 Sumner RG, Phillips JH, Jacoby WJ Jr, Tucker DH: Idiopathic enlargement of the right atrium. Circulation 1965;32:985-991.

-3 Chatrath R, Turek O, Quivers ES, Driscoll DJ, Edwards WD, Danielson GK: Asymptomatic giant right atrial aneurysm. Tex Heart Inst J 2001;28:301-303.

4 Imren Y, Halit V, Kula S, Olgunturk R: Giant right atrial aneurysm: case report. Int J Cardiol 2006;112:e66-e68.

5 Gengsakul A, Sett SS, Hosking MC: Congenital right atrial diverticulum, atrial septal defect within the oval fossa, and complex pulmonary valvar obstruction in an infant with chromosome 8(p23.1) deletion. Cardiol Young 2005; 15:306-308.

6 Kobza R, Oechslin E, Pretre R, Kurz DJ, Jenni R: Enlargement of the right atrium - diverticulum or aneurysm? Eur J Echocardiogr 2003;4:223-225.

$>7$ Chockalingam A, Alagesan R, Gnanavelu G, Dorairajan S, Subramaniam T: Right atrial aneurysm in adults - report of three cases and review of literature. Echocardiography 2004;21:639-643.

$>8$ Blondheim DS, Klein R, Plich M, Marmor AT: Familial idiopathic dilatation of the right atrium with complete atrioventricular block: a new syndrome? Cardiology 2000;94: 224-226.

$>9$ Morrow AG, Behrendt DM: Congenital aneurysm (diverticulum) of the right atrium. Clinical manifestations and results of operative treatment. Circulation 1968;38:124-128.
10 Binder TM, Rosenhek R, Frank H, Gwechenberger M, Maurer G, Baumgartner H: Congenital malformations of the right atrium and the coronary sinus: an analysis based on 103 cases reported in the literature and two additional cases. Chest 2000;117:1740-1748.

11 Da Silva AM, Witsemburg M, Elzenza N, Stewart P: Idiopathic dilatation of the right atrium diagnosed in utero (in Portuguese). Rev Port Cardiol 1992;11:161-163.

12 Reinhardt-Owlya L, Sekarski N, Hurni M, Laurini R, Payot M: Idiopathic dilatation of the right atrium simulating Ebstein's anomaly. A propos of a case diagnosed in utero (in French). Arch Mal Coeur Vaiss 1998;91:645649.

13 Blaysat G, Villain E, Marcon F, Rey C, Lipka J, Lefevre M, Bourlon F: Prognosis and outcome of idiopathic dilatation of the right atrium in children. A cooperative study of 15 cases (in French). Arch Mal Coeur Vaiss 1997;90:645-648.

14 Ohshita T, Chida K, Ueda S, Sakai M, Kuwajima I, Ohkawa S, Esaki M, Takamoto T: An autopsy case of elderly idiopathic enlargement of the right atrium (in Japanese). Nippon Ronen Igakkai Zasshi 1999;36:59-64.

15 Joshi P, Pohlner P: Right atrial aneurysm treated with atrioplasty without using cardiopulmonary bypass in an infant. Eur J Cardiothorac Surg 2005;28:343-345.

16 Moraes F, Santos CL, Lira V, Moraes CR: Congenital aneurysm of the right atrium. Eur J Cardiothorac Surg 2001;19:943-944.

17 Navabi MA, Kiani A, Shabanian R: Congenital right atrial aneurysm in an infant. Pediatr Cardiol 2008;29:998-999.

18 Pernot C, Hoeffel JC, Jacob F: Idiopathic dilatation of the right atrium revealed in childhood by dysrhythmias. Pediatr Radiol 1977; 6:52-54.
19 Divekar A, Soni R, Ross D: Rapidly progressive idiopathic dilation of the right atrium in infancy associated with dynamic obstruction of the airways. Cardiol Young 2002;12: 491-493.

20 Rutledge J, Robertson MA, Kantoch M, Dyck $\mathrm{J}$ : Idiopathic dilation of the right atrium: case report and survey of the literature. Can J Cardiol 1997; 13:855-857.

-21 Marin-Garcia J, Allen RG: Idiopathic dilatation of the right atrium: postoperative follow-up in a child. J Pediatr Surg 1983;18:196198.

22 Marin-Garcia J: Idiopathic dilation of the right atrium. Chest 1981;79:378-379.

23 Gross B, Petrikovsky B, Challenger M: Prenatal diagnosis of an aneurysm of the right atrium. Prenat Diagn 1996;16:1043-1045.

24 Wagner N, Kagan KO, Abele H, Hoopmann M, Kaulitz R, Hofbeck M: Fetal idiopathic dilatation of the right atrium. Ultraschall Med 2011;32:81-82.

25 Tenckhoff L, Stamm SJ, Beckwith JB: Sudden death in idiopathic (congenital) right atrial enlargement. Postmortem findings and review of cases. Circulation 1969;40:227-235.

26 Stressig R, Fimmers R, Eising K, Gembruch U, Kohl T: Preferential streaming of the ductus venosus and inferior caval vein towards the right heart is associated with left heart underdevelopment in human fetuses with left-sided diaphragmatic hernia. Heart 2010; 96:1564-1568.

27 Gold JP, Afifi HY, Ko W, Horner N, Hahn R Congenital giant aneurysms of the left atrial appendage: diagnosis and management. J Card Surg 1996;11:147-150.

28 Barberato SH, Barberato MF, Avila BM, Perretto S, Blume Ld Ldo R, Chamma Neto M: Aneurysm of the right atrial appendage. Arq Bras Cardiol 2002;78:236-241. 